ISSN 2073-8994

www.mdpi.com/journal/symmetry

Article

\title{
Computed NMR Shielding Effects over Fused Aromatic / Antiaromatic Hydrocarbons
}

\author{
Ned H. Martin *, Mathew R. Teague and Katherine H. Mills \\ Department of Chemistry and Biochemistry, University of North Carolina Wilmington, 601 South \\ College Road, Wilmington, NC 28403-5932, USA; E-Mails: mattrteague@ gmail.com (M.R.T.); \\ khm0327@alum.uncw.edu (K.H.M.)
}

* Author to whom correspondence should be addressed; E-Mail: martinn@ uncw.edu.

Received: 14 January 2010; in revised form: 17 March 2010 / Accepted: 19 March 2010 /

Published: 22 March 2010

\begin{abstract}
Through-space isotropic NMR shielding values of a perpendicular diatomic hydrogen probe moved in a $0.5 \AA$ grid $2.5 \AA$ above several polycyclic aromatic/antiaromatic ring and aromatic/aromatic hydrocarbons were computed with Gaussian 03 at the GIAO HF/6-31G(d,p) level. Combinations of benzene fused with cyclobutadiene, with the tropylium ion, and with the cyclopentadienyl anion were investigated. Subtraction of the isolated $\mathrm{H}_{2}$ isotropic value gave shielding increments $(\Delta \sigma)$, which, when plotted against Cartesian coordinates of the probe over each hydrocarbon, gave representations of threedimensional isotropic shielding increment surfaces. The results are related to the degree of bond length alternation, the extent of $\pi$ electron delocalization, and (for the ions) the NPA charge distribution. The shielding increment data are compared to NICS(1) values computed at the same level; both indicate the degree of aromaticity or antiaromaticity of the component rings.
\end{abstract}

Keywords: aromaticity; antiaromaticity; NMR shielding; fused hydrocarbons; GIAO; HF/6-31G(d,p); NICS(1)

\section{Introduction}

The concept of aromaticity encompasses structural, energetic, and magnetic properties of molecules [1]. Hückel [2] noted that molecules having $4 n+2$ delocalized $\pi$ electrons in the periphery of a planar cyclic system possessed the special properties associated with aromaticity. Properties of aromatic 
molecules typically include similar (non-alternating) bond lengths that are intermediate in length between single and double bonds, extra stability compared to isomers with less electron delocalization, and the ability to maintain a diatropic ring current in a magnetic field. The diatropic ring current results in magnetic shielding above and below the plane of the ring. Perhaps the most cited indirect assessment of the ring current effect is the nucleus-independent chemical shift (NICS), developed by Schleyer in 1996 [3]. Aromatic rings give negative NICS values. In contrast, antiaromatic molecules have $4 n \pi$ electrons in a planar conjugated system, but they do not exhibit effects of delocalization of those $\pi$ electrons. Their ring structures have alternating single and double bonds with distinctly different bond lengths, and antiaromatic compounds have less thermodynamic stability than their nonantiaromatic isomers. They display magnetic deshielding above and below the molecular plane caused by a paratropic ring current. Antiaromatic rings have positive NICS values. Several variations on the original isotropic NICS measurement, such as dissected NICS, NICS computed $1 \AA$ above the ring center, and NICS $\pi \mathrm{zz}$ have resulted in improved methods of assessing ring current and therefore aromaticity and antiaromaticity [4-6]. Another NICS method employs the component of the shielding tensor that is perpendicular to the plane of the conjugated system [7]; this has the advantage of minimizing sigma bond contributions and therefore better characterizing the $\pi$ electron ring current effects.

It is well known that polycyclic aromatic hydrocarbons have substantial through-space NMR shielding effects above the molecular plane [5, 8, 9]. In addition, the magnetic consequences of some fused aromatic-antiaromatic ring systems have been explored employing NICS [10,11] or a grid of NICS represented visually as isochemical shielding surfaces (ICSS) [12]. Stanger has demonstrated the utility of plotting NICS values scanned vertically over ring midpoints to better differentiate between antiaromatic and aromatic systems [13]. In this paper we present results of through-space isotropic magnetic shielding calculations of a molecular probe over multi-ring fused systems containing various numbers of benzene (aromatic) rings fused with various numbers of cyclobutadiene (antiaromatic) rings. Eight of these structures are shown in Figure 1 along with benzene and cyclobutadiene. We also have examined magnetic shielding over structures having one or more benzene rings fused with an ionic aromatic ring: either cyclopentadienyl anion or cycloheptatrienyl (tropylium) cation. The five structures of this category in this study are shown in Figure 2 along with.cyclopentadienyl anion and cycloheptatrienyl (tropylium) cation.

A molecular probe of shielding effects has been useful for distinguishing between aromatic and antiaromatic systems [14], and good correlations have been obtained between shielding effects on a molecular probe and other measures of aromaticity in heterocyclic systems [15, 16]. Furthermore, use of a molecular probe allows prediction of chemical shift effects on protons as a function of their position over the ring in question. For these reasons, we have employed a molecular probe to measure the extent of aromaticity (or antiaromaticity) of the structures in this study.

The structures in Figure 1 other than benzene and cyclobutadiene have one or more four-membered rings fused to one or more benzene rings, and thus may be subject to the long-debated Mills-Nixon effect [17]. This postulate states that annelation of small rings onto benzene induces significant alternation of bond lengths of the six-membered ring because of strain associated with bond angle deformation. This concept, which was proposed when benzene was thought by many to be an equilibrating mixture of valence tautomers, has generally been dismissed on the basis of more recent 
experimental and computational work, however [18-20]. Fowler et al. have computed ring current densities of benzene fused with several small-ring hydrocarbons, and have shown that fusion of benzene with one or more cyclobutadiene rings disrupts the benzene ring current, but no disruption in the benzene ring current is observed when only saturated small rings are fused [21]. In his latest of a series of seminal contributions to our understanding of both aromaticity and symmetry, Schleyer, in association with Corminboeuf, reported results of a new method to assess the effects of electron delocalization on magnetic shielding effects in conjugated hydrocarbons using block-localized wavefunctions [22]. Using that technique, it was confirmed for benzene that $\pi$ electron delocalization, rather than bond length similarity or dissimilarity (as in the hypothetical 1,3,5-cyclohexatriene), is the major contributor to the characteristic downfield NMR chemical shift of aryl protons.

Figure 1. Structures of the fused aromatic-antiaromatic hydrocarbons in the study plus benzene and cyclobutadiene. Computed bond lengths (in $\AA$ ) are included.

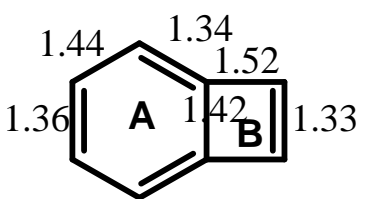

1

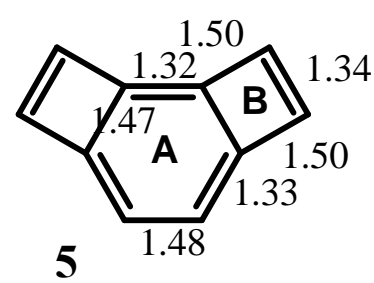<smiles>c1ccccc1</smiles>

2

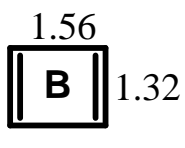

3

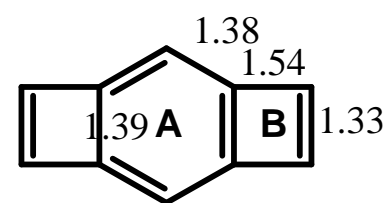

4

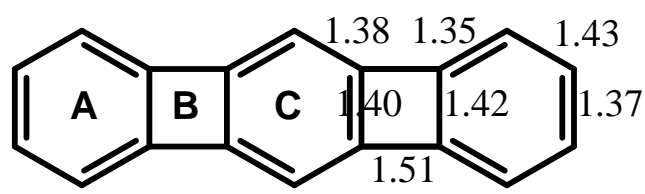

8
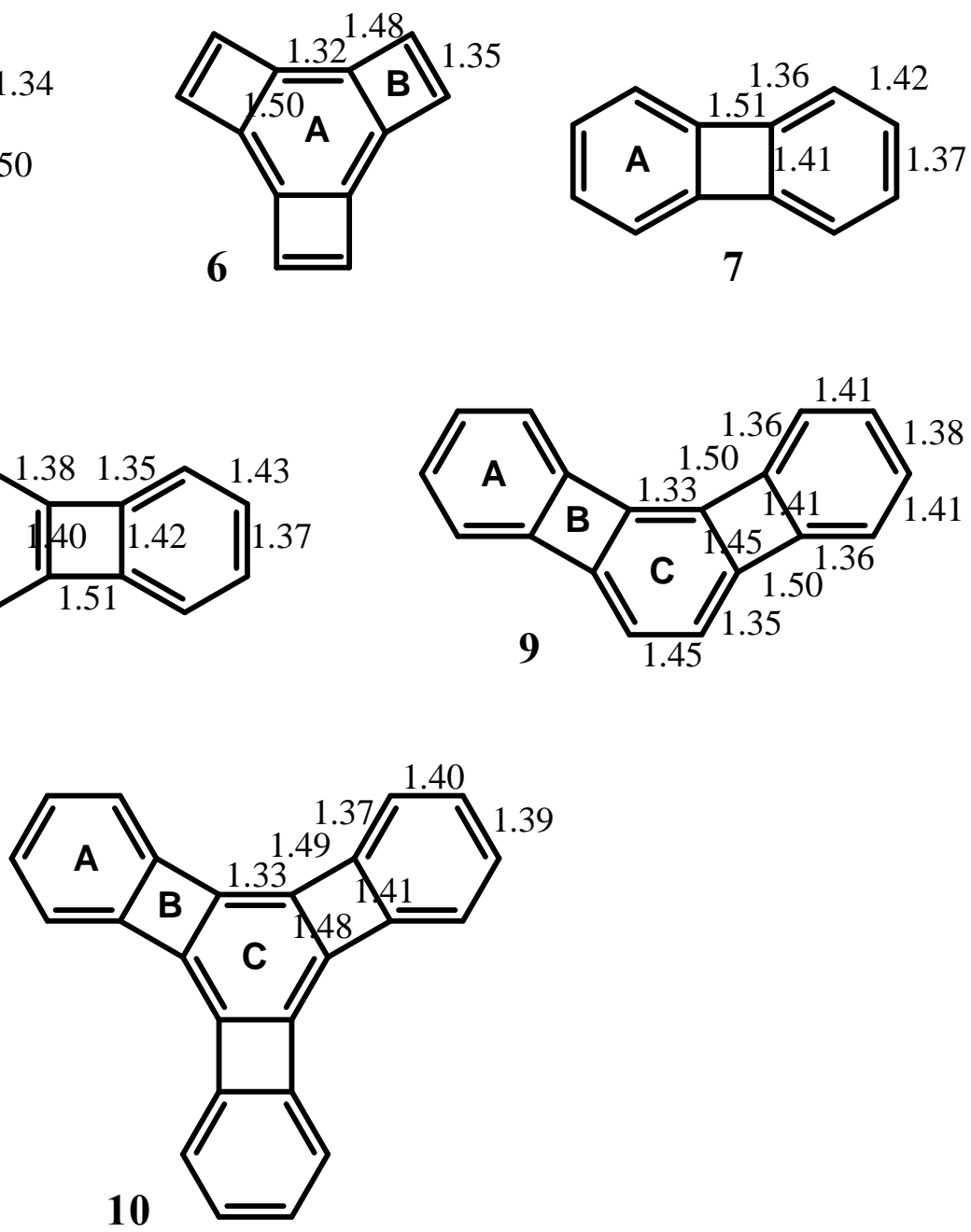
Through-space magnetic shielding effects were also computed over structures having one or more benzene rings fused with an ionic aromatic ring, either cyclopentadienyl anion or cycloheptatrienyl (tropylium) cation and the parent ionic aromatic hydrocarbons themselves. The five structures of this category in this study along with their parent ionic aromatic hydrocarbons are shown in Figure 2.

Figure 2. Structures of the fused benzene-ionic aromatic hydrocarbons and their parent ionic aromatic hydrocarbons in the study (11-17). Computed natural population analysis charges (in e) of the carbon atoms are indicated.

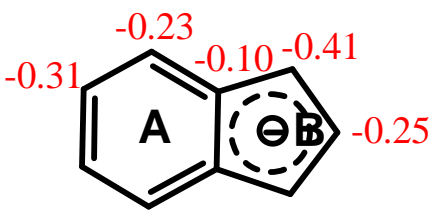

11

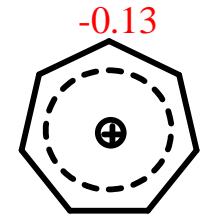

14

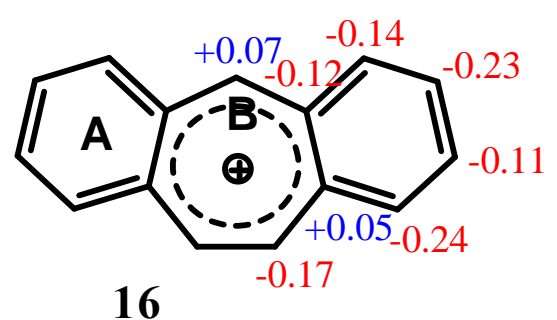

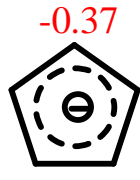

12

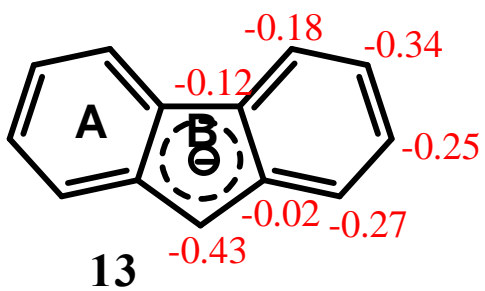

13

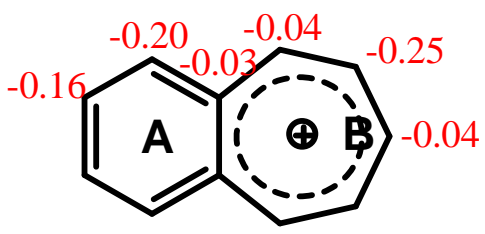

15

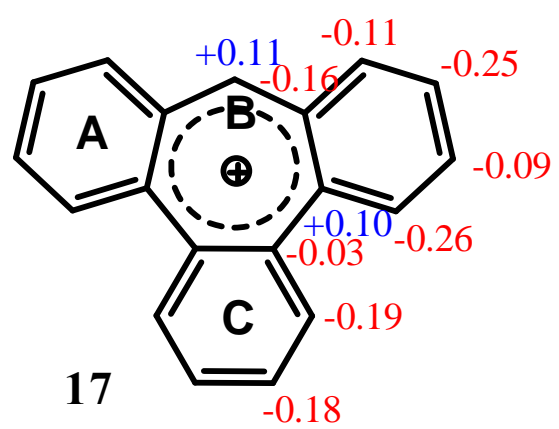

\section{Results and Discussion}

\subsection{Benzene fused to cyclobutadiene}

Structure 1 (Figure 1) has a benzene ring fused to cyclobutadiene. Its $2.5 \AA$ isotropic shielding increment surface (in ppm; see Computational Section), shown in Figure 3a, consists of a mound of moderate shielding $(0.71 \mathrm{ppm})$ over the benzene ring with substantial deshielding $(-1.72 \mathrm{ppm})$ over the $\pi$ bond of the cyclobutadiene ring. For reference, previous calculations have shown that benzene 2 has a maximum shielding increment value of $2.96 \mathrm{ppm}$ at $2.5 \AA$; cyclobutadiene 3 has a shielding minimum (maximum deshielding) at $2.5 \AA$ of -2.83 ppm [14]. These appear as Figure $4 \mathrm{a}$ and $4 \mathrm{~b}$, respectively. Elguero et al. reported a similar value $(2.61 \mathrm{ppm})$ for benzene using methane as a probe [23]. Bond length calculations show moderate bond length alternation (1.34 $\AA$ to $1.44 \AA ; \Delta d=0.10 \AA$; $\Delta \mathrm{d}$ here only refers to the difference between the longest and shortest bond) in the benzene ring of benzocyclobutadiene $\mathbf{1}$ as indicated by the placement of the double bonds in the structure. For reference purposes, the bond lengths of the carbon-carbon bonds of benzene computed with the same level of theory and basis set are $1.39 \AA$. The four-membered ring displays substantial bond length 
alternation ( $1.33 \AA$ for the external bond; $1.52 \AA$ for the bonds to the benzene ring; $\Delta \mathrm{d}=0.19 \AA$ ). For reference, the computed bond lengths of cyclobutadiene are $1.32 \AA$ and $1.56 \AA(\Delta d=0.24 \AA)$. Thus, the four-membered ring in $\mathbf{1}$ has a highly localized $\pi$ bond, as expected. The ring current density map concurs [21]; the benzene ring has a diminished diatropic ring current and the cyclobutadiene ring has a strong paratropic current. No crystallographic data are available.

Figure 3. Isotropic shielding increment surfaces of (a) 1 and (b) 4.

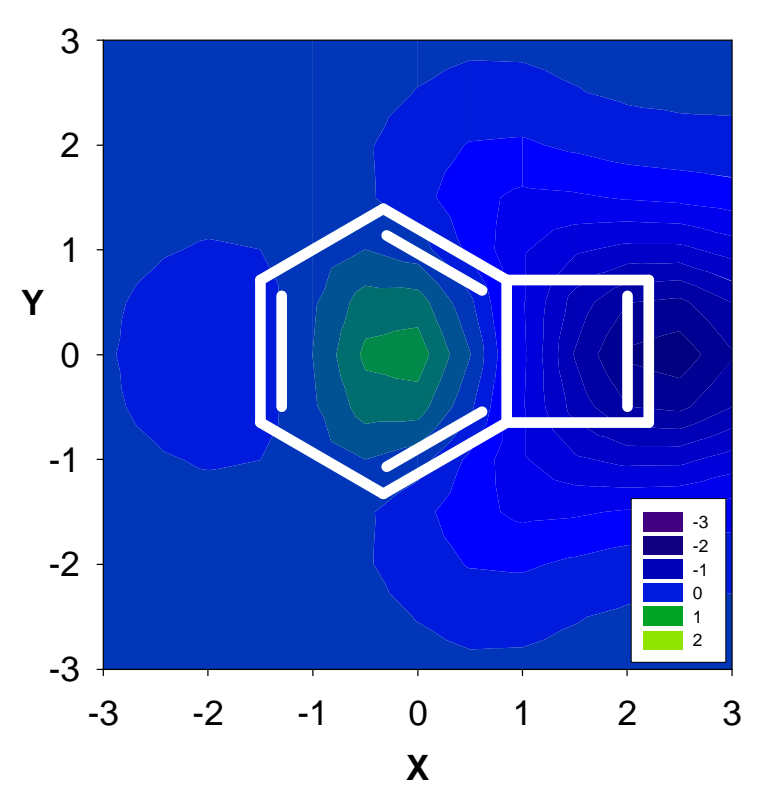

(a)

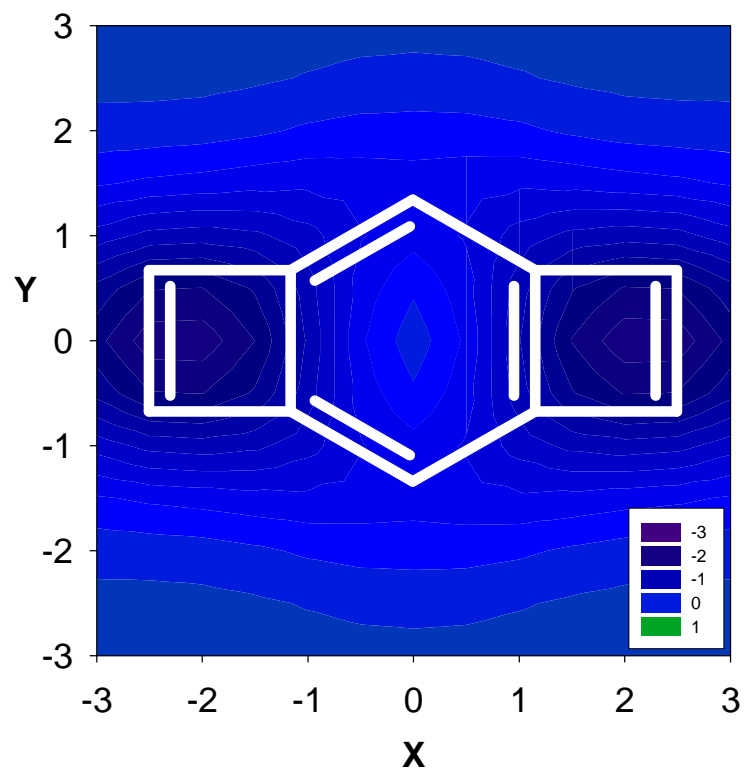

(b)

Structure $\mathbf{4}$ has two cyclobutadiene units fused to opposite faces of benzene. The isotropic shielding increment surface is shown in Figure $3 b$. Addition of the second cyclobutadiene moeity results in significantly diminished shielding over the benzene ring $(\Delta \sigma=-0.08 \mathrm{ppm})$, and enhanced deshielding (-2.11.ppm) over the midpoints of each of the cyclobutadiene portions relative to structure $\mathbf{1}$. Bond length calculations at the optimized geometry show considerable bond length equalization among the benzene ring bonds (range $=1.38 \AA$ to $1.39 \AA$ ). In contrast, the four-membered ring bonds have substantial bond length alternation ( $1.33 \AA$ to $1.54 \AA ; \Delta d=0.21 \AA$ ), as expected. This suggests a localized $\pi$ bond for the four-membered ring consistent with the observed deshielding effect, but delocalized $\pi$ electrons in the central (six-membered) ring, despite the observed deshielding effect over that ring, which is considerably enhanced by the proximity of two strongly deshielding carbon-carbon double bonds. Current density maps of this structure reveal the same effect, dominance of the paratropic ring current of the butadiene ring [21]. No crystallographic data are available for 4 .

Structure 5 (Figure 5a) has two cyclobutadiene rings fused to a benzene ring along alternating faces of benzene. Only deshielding is observed over structure 5, there is no shielding. Regions of moderate deshielding (-0.6 to $-0.8 \mathrm{ppm}$ ) are seen near the external localized double bonds of the cyclobutadiene rings as well as near the ring bonds of the central six-membered ring that alternate with those fused to cyclobutadienes. The other ring bonds of the six-membered ring have somewhat less deshielding $(-0.4$ ppm), and the midpoint of that ring has the least deshielding $(-0.29 \mathrm{ppm})$. These results suggest substantial localization of $\pi$ electron density in the bonds that alternate with the ring fusion locations, 
as indicated by placement of the double bonds in the resonance form of $\mathbf{5}$ shown in Figures 1 and 5(a). This is consistent with bond length calculations for the six-membered ring ( $\Delta \mathrm{d}=0.15 \AA$ ).

Figure 4. Isotropic shielding increment surfaces of (a) benzene 2 and (b) cyclobutadiene 3.

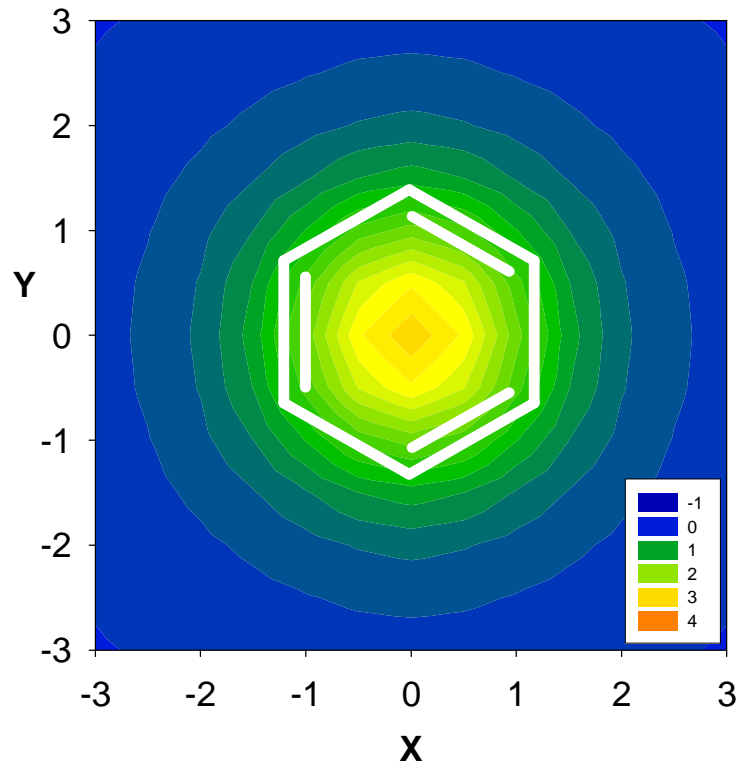

(a)

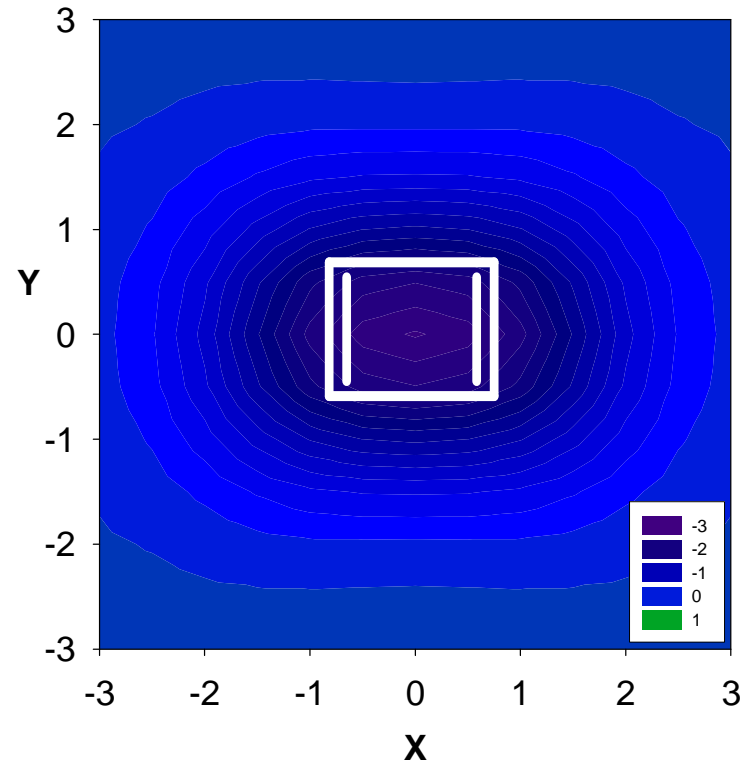

(b)

Current density maps concur [21] with complete bond localization. Bond length alternation diminishes the aromaticity of the central ring, but it also prevents the two four-membered rings from being antiaromatic. Bond length calculations confirm this. The three six-membered ring bonds that alternate with the ring fusion fusion bonds have lengths of 1.30 to $1.33 \AA$; the ring fusion bonds are $1.47 \AA$; the other bond is $1.48 \AA(\Delta \mathrm{d}=0.18 \AA)$. The four membered ring bonds have computed bond lengths of $1.34 \AA$ and $1.50 \AA(\Delta \mathrm{d}=0.16 \AA)$. No crystallographic data are available for 5 .

Figure 5. Isotropic shielding increment surfaces of (a) 5 and (b) 6.

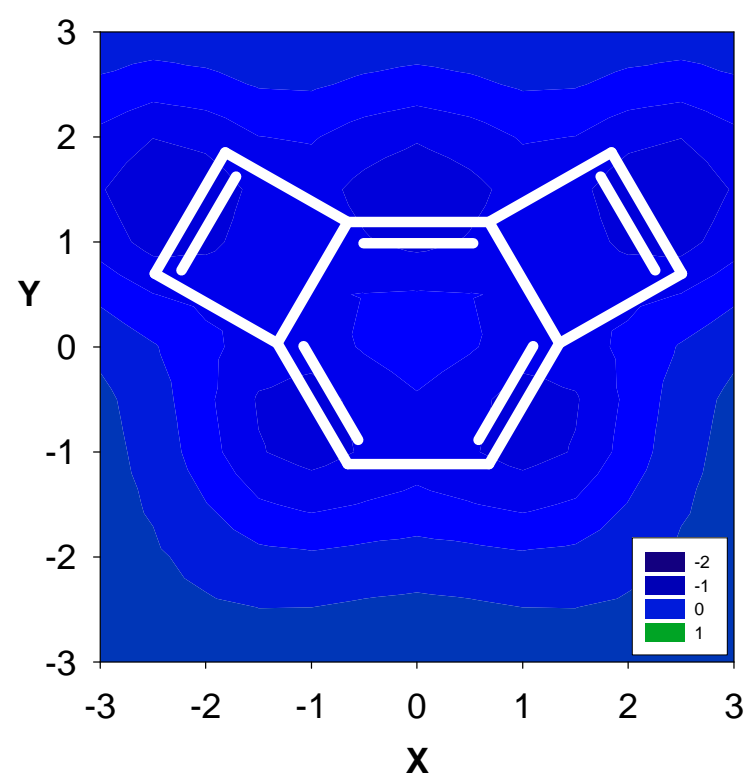

(a)

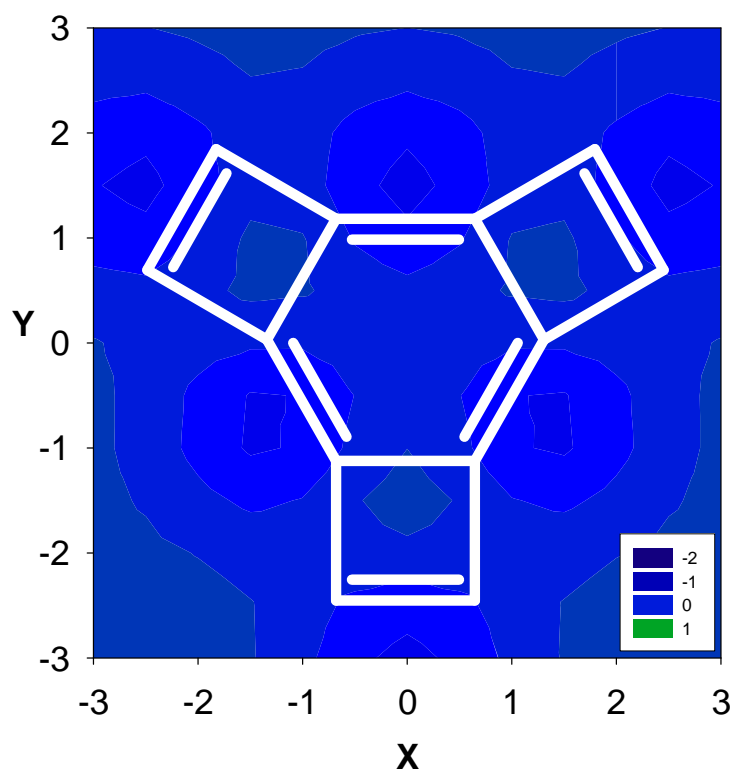

(b) 
The isotropic shielding increment surface of structure 6 (Figure 5b) has similar features and for similar reasons. Moderate deshielding $(-0.47 \mathrm{ppm})$ is observed in the vicinity of the external $\pi$ bonds of the four-membered rings as well as over the $\pi$ bonds of the benzene ring that alternate with the ring fusion sites. Slight deshielding is seen over the center of the six-membered ring (-0.05 ppm) as well as over the center of the four membered rings $(-0.01 \mathrm{ppm})$. Bond length calculations substantiate complete localization of $\pi$ bonding. The bonds that are fused with four-membered rings have lengths of $1.50 \AA$, whereas the alternating bonds in the six-membered ring have lengths of $1.32 \AA(\Delta \mathrm{d}=0.18$ $\AA$ ). The latter bond is even shorter than the external double bond in the four-membered ring (1.35 $\AA$ ). Again, distortion of the symmetry and $\pi$ bond localization both occur in the benzene ring. It is apparently energetically more favorable to prevent the antiaromaticity of three cyclobutadiene rings than to allow the aromaticity of one benzene ring. No crystallographic data are available for $\mathbf{6}$. Ring current density maps also suggest the presence of highly localized $\pi$ bonds throughout [21].

Biphenylene 7 has an isotropic shielding increment surface that combines the features expected for two aromatic rings with those of a central antiaromatic ring (Figure 6a). Substantial shielding (1.55 ppm) is observed over the middle of each benzene ring, and moderate deshielding ( $-0.41 \mathrm{ppm})$ is observed over the middle of the four-membered ring. Bond lengths are nearly normal for delocalized $\pi$ bonds of the benzene rings; the range of bond lengths in the benzene rings is moderate: $1.36 \AA$ to 1.42 $\AA(\Delta \mathrm{d}=0.06 \AA)$, consistent with the decreased shielding effect relative to benzene. The bond length in the central four-membered ring is $1.51 \AA$ between the benzene rings and are $1.41 \AA$ for the bonds shared with the benzene rings. Thus the shielding effects are dominated by the moderate degree of aromaticity of the two benzene rings, with little effect of the deshielding four-membered ring, as reported by Kleinpeter using a somewhat different method [12]. X-ray data generally agree with the computed bond lengths: 1.37 to $1.43 \AA$ range $(\Delta d=0.06 \AA)$ for the six-membered ring; $1.51 \AA$ between the benzene rings and $1.43 \AA$ for the bonds shared with the benzene rings [24, 25]. Thus, with a four-membered ring between benzene rings, the latter retain much of their aromaticity.

Figure 6. Isotropic shielding increment surfaces of (a) 7 and (b) 8.

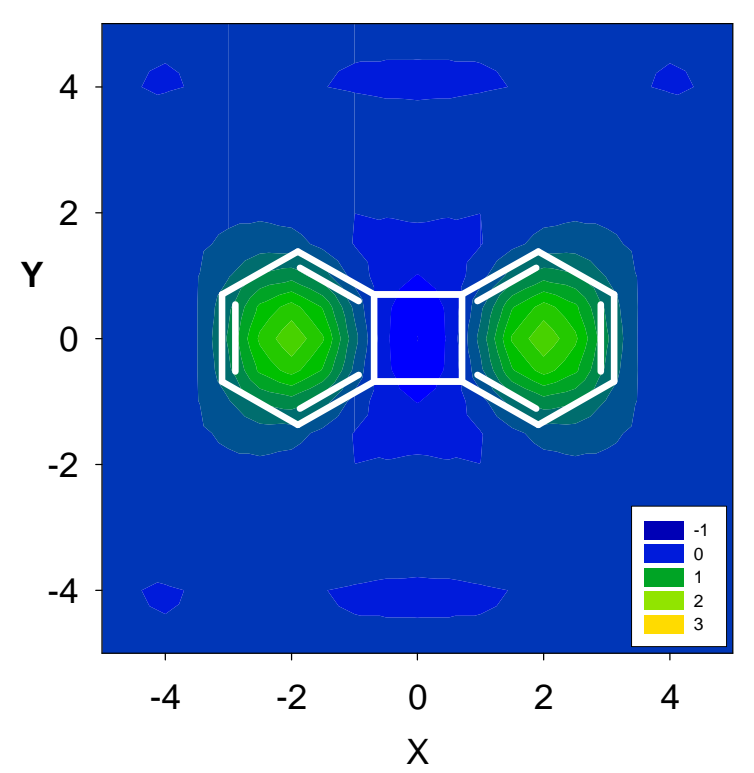

(a)

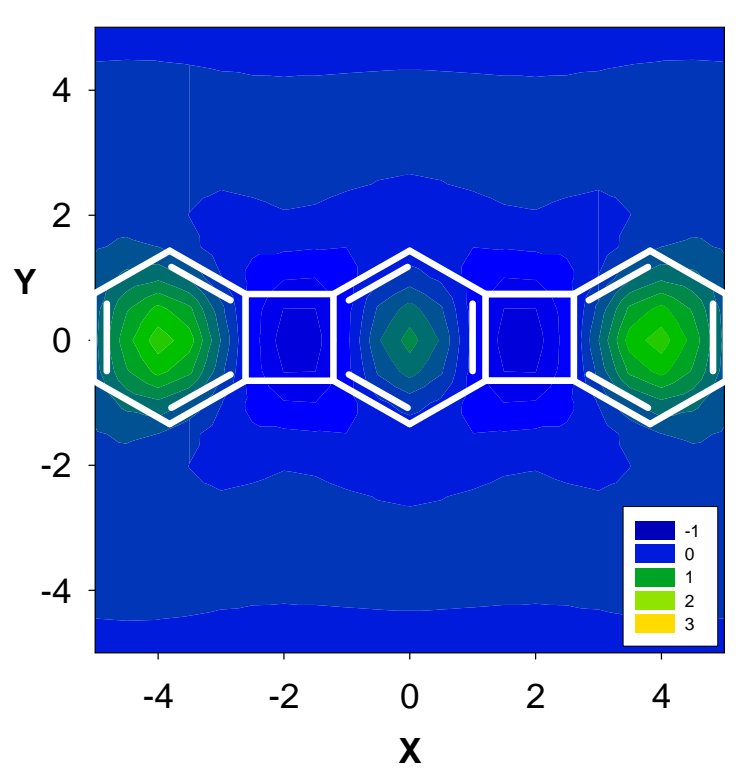

(b) 
Structure $\mathbf{8}$ has three benzene rings and two four-membered rings arranged symmetrically and linearly. The isotropic shielding surface of $\mathbf{8}$ is shown in Figure 6b. The outer benzene rings show substantial shielding $(1.30 \mathrm{ppm})$ over their center, but the central benzene ring shows only moderate shielding $(0.69 \mathrm{ppm})$. The four-membered rings display moderate deshielding effects $(-0.73 \mathrm{ppm})$. Bond length alternation is moderate in the outer benzene rings $(1.35 \AA$ to $1.43 \AA ; \Delta \mathrm{d}=0.08 \AA$ ) and matches the double bond locations shown in the structure but is minimal in the central benzene ring (1.38 $\AA$ to $1.40 \AA ; \Delta \mathrm{d}=0.02 \AA$ ) The four-membered rings have bond lengths of $1.42 \AA$ and $1.40 \AA$ (shared with the outer and inner benzo rings, respectively) and $1.51 \AA(\Delta d=0.11 \AA$ ) between the benzene rings. In general, the shielding (and deshielding) effects in $\mathbf{8}$ seem to be additive, yet it is curious that the central benzene ring, which has very little bond length alternation, causes so little shielding. It is likely that its shielding effect is doubly diminished by the adjacency of two fourmembered rings, each causing deshielding that extends past the four-membered ring. X-ray analysis of a tetrasilylated derivative also revealed moderate bond length alternation in the outer six-membered rings ( $1.36 \AA$ to $1.44 \AA$; $\Delta \mathrm{d}=0.08 \AA$ ) with considerable bond length similarity in the central benzene ring (1.39 ̊̊ to $1.41 \AA)$ [26].

Structure 9 has the same number of four- and six-membered rings as in $\mathbf{8}$, but they are arranged in a $\mathrm{V}$-shape. The isotropic shielding surface of $\mathbf{9}$ is reminiscent of what was observed for $\mathbf{5}$, to which it bears some resemblance. The outer benzene rings of 9 display substantial shielding (2.01 ppm), as expected (Figure $7 \mathrm{a})$. There is slight deshielding $(-0.13 \mathrm{ppm})$ over the midpoint of the four-membered rings. The most interesting aspect of the isotropic shielding increment surface is the appearance of moderate deshielding $(-0.45 \mathrm{ppm})$ over the bond in the central six-membered ring that connects the four-membered rings and only slight shielding $(0.28 \mathrm{ppm})$ over the center of that six-membered ring. This can be explained by substantial $\pi$ bond localization in the central ring, as verified by bond length calculations. The computed bond lengths in the middle six-membered ring vary from $1.33 \AA$ to $1.45 \AA$

Figure 7. Isotropic shielding increment surfaces of (a) 9 and (b) 10.

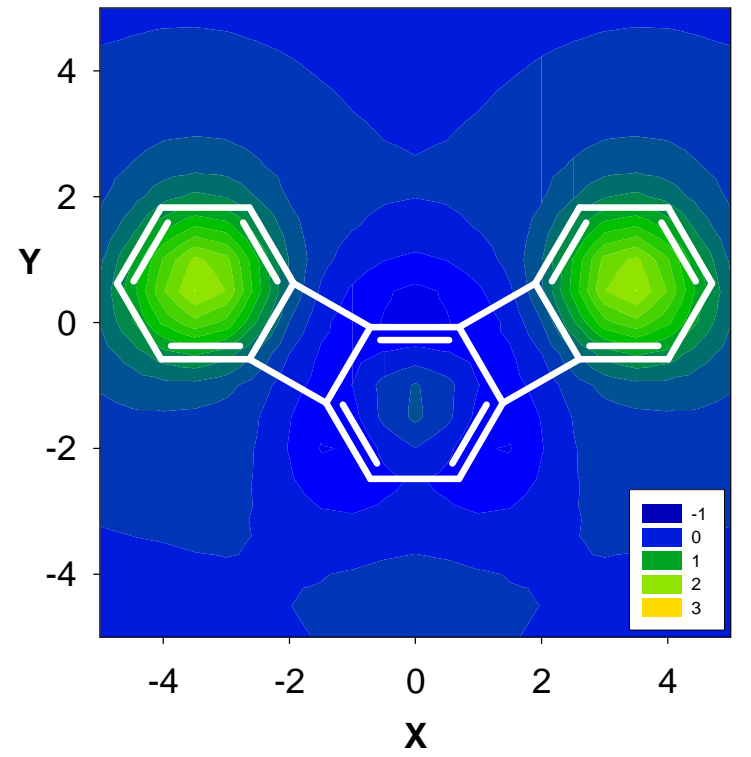

(a)

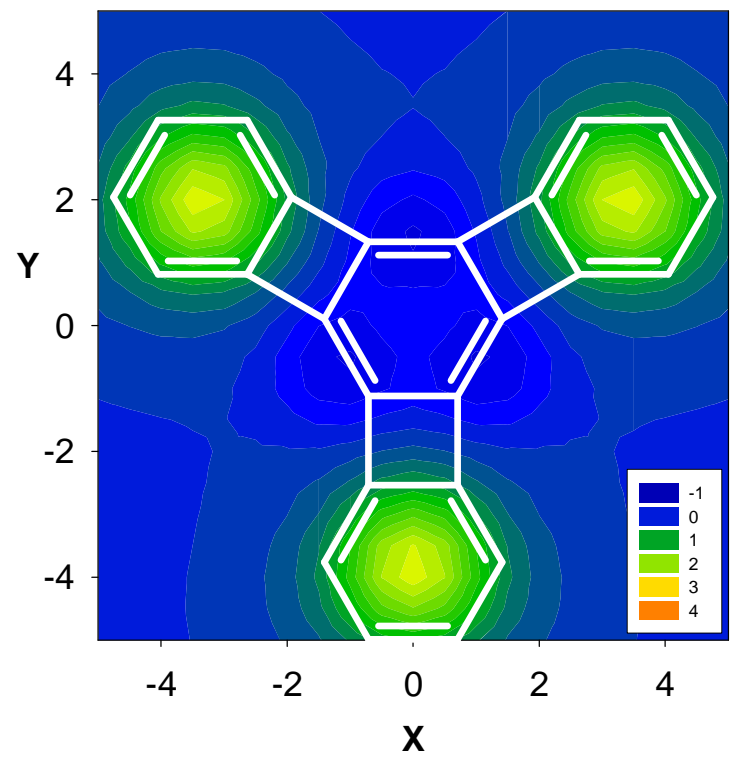

(b) 
$(\Delta \mathrm{d}=0.12 \AA)$, and alternate in length according to the locations of double bonds shown in the structure. In contrast, the computed bond lengths in the terminal benzene rings vary only slightly, from $1.36 \AA$ to $1.41 \AA(\Delta \mathrm{d}=0.05 \AA)$. Thus the outer benzene rings are aromatic in nature, but the central six membered ring is not aromatic. Kleinpeter drew a similar conclusion [12, 27]. Interestingly, the fourmembered rings have relatively little computed bond length alternation $(\Delta d=0.09 \AA)$ compared to cyclobutadiene $(\Delta \mathrm{d}=0.24 \AA$ ), with the bond forming the ring juncture to the middle ring $(1.45 \AA$ ) being midway in length between a single bond and a double bond, the bond between the six-membered rings $(1.50 \AA)$ being more single bond-like in length and the ring juncture to the outer benzene ring having a bond length (1.41 $\AA$ ) like that of a delocalized benzene ring. Therefore, the four-membered rings in this structure do not have $4 \pi$ electrons needed for antiaromaticity; they behave more like cyclobutane rings, explaining their lack of (de)shielding effect. X-ray data corroborate the calculated bond lengths. The middle six-membered ring has considerable bond length variation: $1.33 \AA$ to $1.45 \AA$ $(\Delta \mathrm{d}=0.12 \AA)$; the outer benzene rings show much less bond length alternation: $1.36 \AA$ to $1.41 \AA(\Delta \mathrm{d}=$ $0.05 \AA$ ). X-ray data shows $1.50 \AA$ for the bond connecting the six-membered rings, and $1.45 \AA$ and $1.44 \AA$ for the four-membered ring bonds common to the inner and outer six-membered ring, respectively [28], generally consistent with computed bond lengths.

The addition of a fourth benzene ring and a third four-membered ring to the previous structure gives structure 10. The isotropic shielding surface is shown in Figure 7b. The external benzene rings show substantial shielding $(2.39 \mathrm{ppm})$ over their midpoints, but the central six-membered ring gives rise to slight deshielding $(-0.27 \mathrm{ppm})$ at its midpoint and moderate deshielding $(-0.64 \mathrm{ppm})$ over the bonds connecting the four-membered rings. Kleinpeter reported similar results [12, 27], and Fowler's ring current density calculations [21, 29] concur with the lack of aromaticity of the central six-membered ring. This structure causes very slight shielding $(0.18 \mathrm{ppm})$ over the midpoint of the four- membered rings which increases to moderate deshielding near the fusion with the central six-membered ring, reflecting the (de)shielding effects of the non-aromatic six-membered ring to which they are fused. Bond length calculations substantiate the idea that the outer benzene rings are highly aromatic (bond lengths range from $1.37 \AA$ to $1.41 \AA ; \Delta d=0.04 \AA$ ), but that the central six-membered ring ring is not aromatic (bond lengths alternate substantially, ranging from $1.33 \AA$ to $1.48 \AA ; \Delta d=0.15 \AA$. The fourmembered rings have little bond length variation: $1.48 \AA$ to $1.49 \AA$ except for the bond shared with the external benzene rings, which is shorter $(1.41 \AA)$ because it is part of an aromatic system. X-ray analysis of a trimethylsilyl derivative [30] shows relatively small bond length alternation in the outer benzene rings ( $1.36 \AA$ to $1.41 \AA$, except for the bond between the trimethylsilyl-substituted carbons, which is $1.44 \AA$, elongated to accommodate the bulky trimethylsilyl groups). In contrast, the central six-membered ring shows substantial bond length alternation ( $1.33 \AA$ to $1.50 \AA$; $\Delta \mathrm{d}=0.17 \AA$ ).

Computed shielding increments indicate that structures 1, 4, 5 and 6 have very little aromaticity in their six-membered rings, whereas structure 7-10 have six-membered rings that are much more aromatic. The major difference between these two groups of structures is that in structures $\mathbf{1 , 4 , 5}$ and $\mathbf{6}$, the four membered rings have at least one double bond whereas the four-membered rings in 7-10 are more cyclobutane-like. Computed ring current densities of benzene fused with several small-ring hydrocarbons show that fusion of benzene with one or more cyclobutadiene rings disrupts the benzene ring current, but no disruption in the benzene ring current is observed when only saturated small rings are fused [21]. The two methods concur. Furthermore, the antiaromaticity of cyclobutene rings fused to 
alternate faces of benzene diminishes as the number of such rings increases (as in $\mathbf{5}$ and $\mathbf{6}$ ). Fusion of cyclobutene to opposite faces of benzene (as in 4), on the other hand, increases their antiaromaticity compared to benzocyclobutadiene $\mathbf{1}$.

Computed $\Delta \sigma$ values $2.5 \AA$ above the ring midpoints and NICS(1) values for structures 1-10 are collected in Table 1. These two measures of aromaticity correlate well $(r=0.98$, Figure 8$)$ for the sixmembered rings in structures $\mathbf{1 - 1 0}$, and reasonably well $(\mathrm{r}=0.92)$ for the four-membered rings. The latter correlation improves ( $r=0.99$; not shown) if only the external four-membered rings (those in structures 1, 4, 5 and 6) are correlated. These high levels of correlation are not unexpected, as both techniques measure isotropic shielding using the same GIAO method. The difference is that $\Delta \sigma$ values employ a molecular probe, whereas NICS(1) measurements use a point in space (Bq; a ghost atom). Use of a molecular probe (i.e., a probe having a polarizable bond) has been shown to provide more accurate chemical shift predictions than ghost atoms [31].

Table 1. Shielding increments $2.5 \AA$ over ring midpoints (and NICS(1) values) as labeled in Figure 1.

$\Delta \sigma$ and $(\operatorname{NICS}(1))$ in ppm above center of ring:

$\begin{array}{llll}\text { Structure } & \text { A } & \text { B } & \text { C }\end{array}$

\begin{tabular}{lcll}
\hline $\mathbf{1}$ & $0.71(-5.52)$ & $-1.56(10.70)$ & -- \\
$\mathbf{2}$ & $2.96(-12.90)$ & -- & - \\
$\mathbf{3}$ & -- & $-2.83(17.42)$ & -- \\
$\mathbf{4}$ & $-0.08(-4.43)$ & $-2.11(13.46)$ & -- \\
$\mathbf{5}$ & $-0.29(-0.91)$ & $-0.54(1.01)$ & -- \\
$\mathbf{6}$ & $-0.05(-1.92)$ & $-0.01(-2.85)$ & - \\
$\mathbf{7}$ & $1.55(-8.13)$ & $-0.41(7.50)$ & $0.69(-5.63)$ \\
$\mathbf{8}$ & $1.30(-7.33)$ & $-0.73(7.86)$ & $0.28(-3.17)$ \\
$\mathbf{9}$ & $2.01(-9.82)$ & $-0.13(3.74)$ & $-0.27(-0.79)$
\end{tabular}


Figure 8. Graph of $\Delta \sigma$ versus NICS(1) over the midpoints of each ring size in structures 1-10. Blue triangles represent six-membered rings; red squares are four-membered rings.

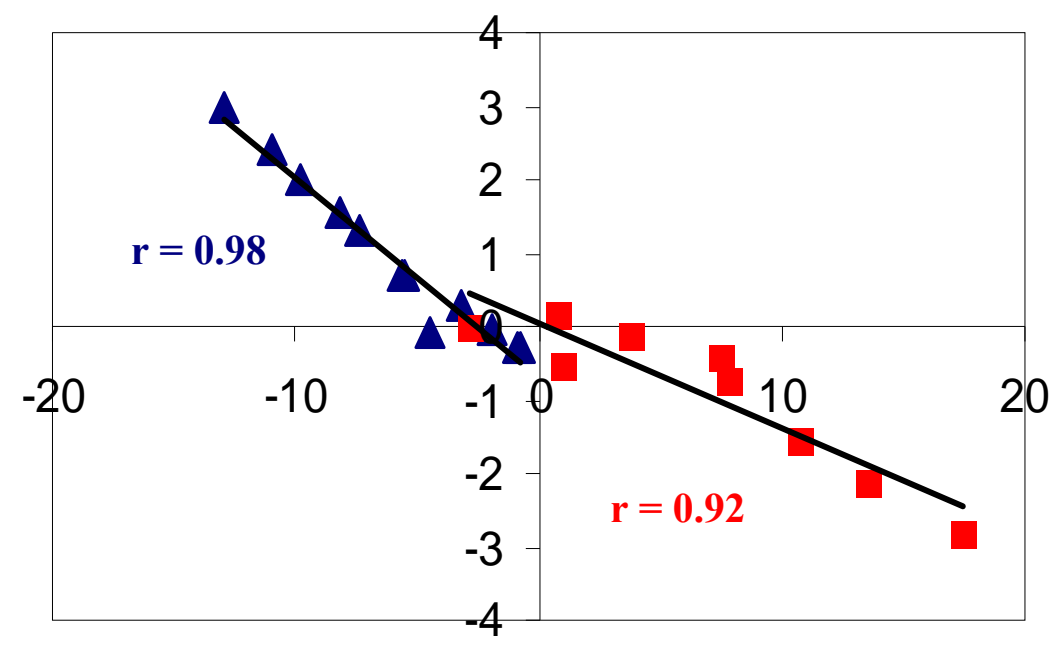

\subsection{Benzene fused to cyclopentadienyl anion}

The indenyl anion 11 provides an unexpected isotropic shielding increment surface. Anions generally cause deshielding of a molecular probe because of the electrostatic repulsion and resulting bond polarization of the proximal hydrogen of the probe molecule [14]. However, Figure 9a shows a peanut-shaped mound of shielding over the center of the structure, with a maximum shielding value of $2.48 \mathrm{ppm}$ and substantial shielding over the centers of both the benzene ring (2.36 ppm) and the fivemembered ring $(2.32 \mathrm{ppm})$. As a point of reference, the reported $\Delta \sigma$ value over cyclopentadienyl anion 12 is 1.17 ppm [14], Figure 10a. This suggests a high degree of charge and $\pi$ electron delocalization resulting in substantial aromaticity and greater shielding effect for the indenyl anion. The computed bond lengths range from $1.37 \AA$ to $1.44 \AA ; \Delta \mathrm{d}=0.07 \AA$, corroborating this suggestion. Natural population analysis (npa) charge [32] calculations (Figure 2) on the carbon atoms vary from -0.23 e to $-0.41 \mathrm{e}$, except for the for the ring juncture carbon atoms which have a computed npa charge of $-0.10 \mathrm{e}$. The mean charge per $\mathrm{C}-\mathrm{H}$ group (excluding the charges on ring juncture carbon atoms) is -0.07 e for the benzene ring and -0.17 e for the cyclopentadienyl ring. Small regions of deshielding ( $-0.75 \mathrm{ppm})$ are evident beyond the benzylic carbons, which bear the greatest negative charge. This is consistent with electrostatic deshielding.

The fluorenyl anion 13 shows a symmetrical shielding surface (Figure 9b). In addition to an elongated slightly curved mound of shielding over the three rings (with maximum shielding of $3.04 \mathrm{ppm})$, there is a distinct region of deshielding $(-0.71 \mathrm{ppm})$ centered $1.5 \AA$ A beyond the bisbenzylic carbon. This region of deshielding indicates substantial negative charge localization on the bisbenzylic carbon of the fluorenyl anion. Natural population analysis (npa) charge calculations (Figure 2) verified this; the npa charge on the benzylic carbon is -0.43 e, nearly 0.10 e more negative than the charge on any other carbon atom in the structure. The mean charge per $\mathrm{C}-\mathrm{H}$ group (excluding the charges on ring juncture carbon atoms) is -0.06 e for the benzene ring and -0.24 e for the cyclopentadienyl ring, consistent with the deshielding region beyond the benzylic carbon. 
Figure 9. Isotropic shielding increment surfaces of (a) 11 and (b) 13.

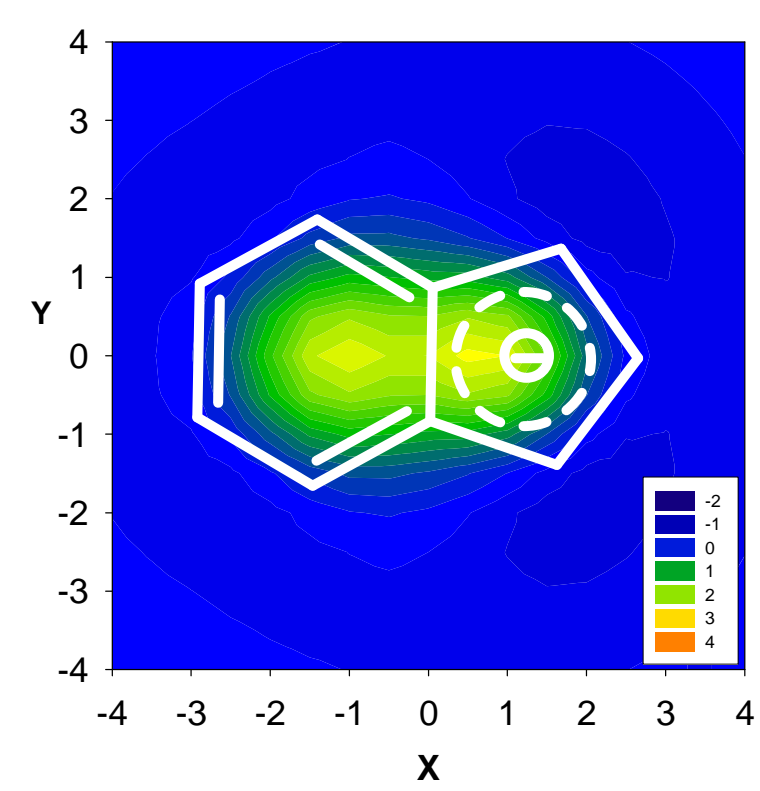

(a)

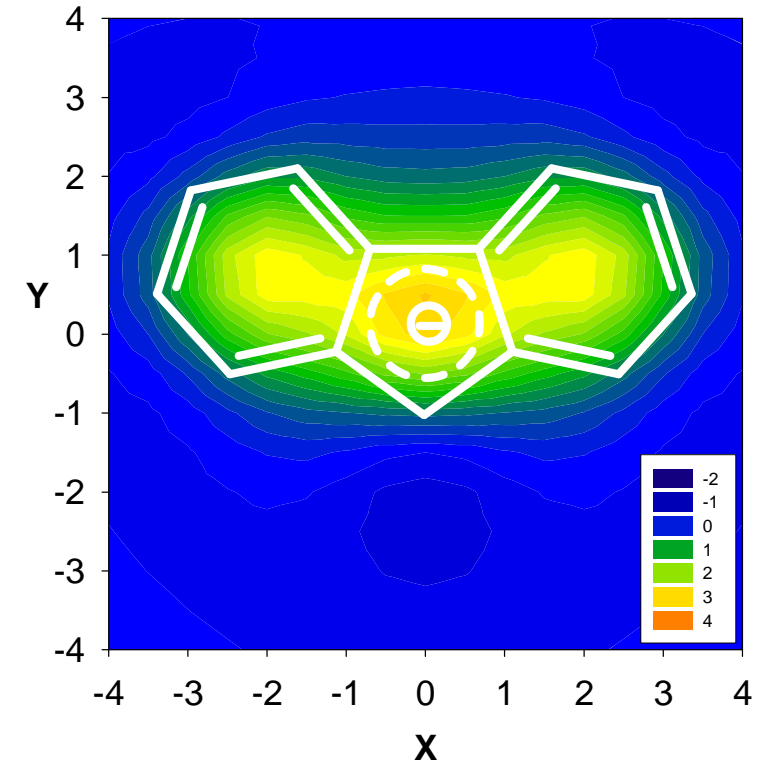

(b)

Figure 10. Isotropic shielding increment surfaces of (a) cyclopentadienyl anion $\mathbf{1 2}$ and (b) tropylium ion 14.

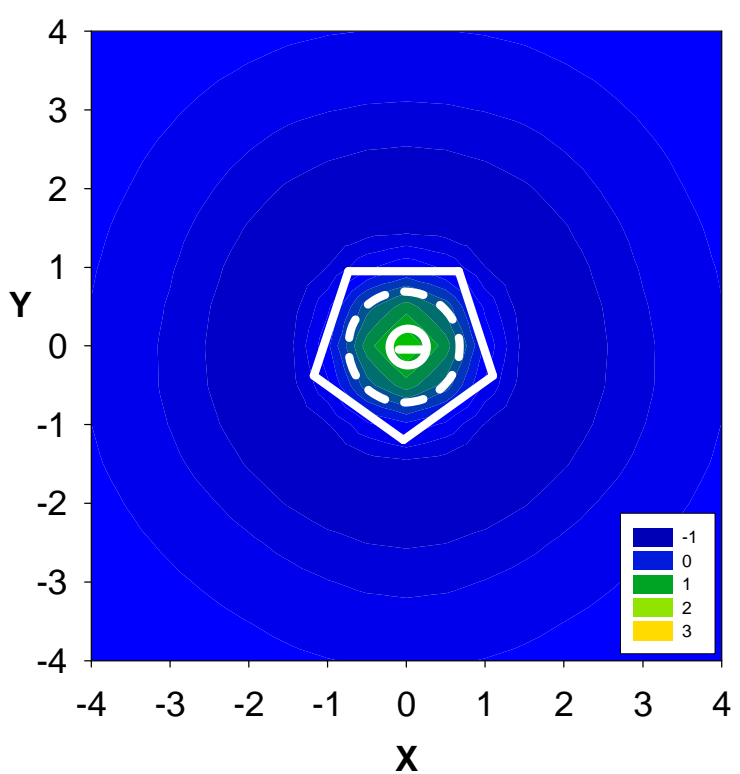

(a)

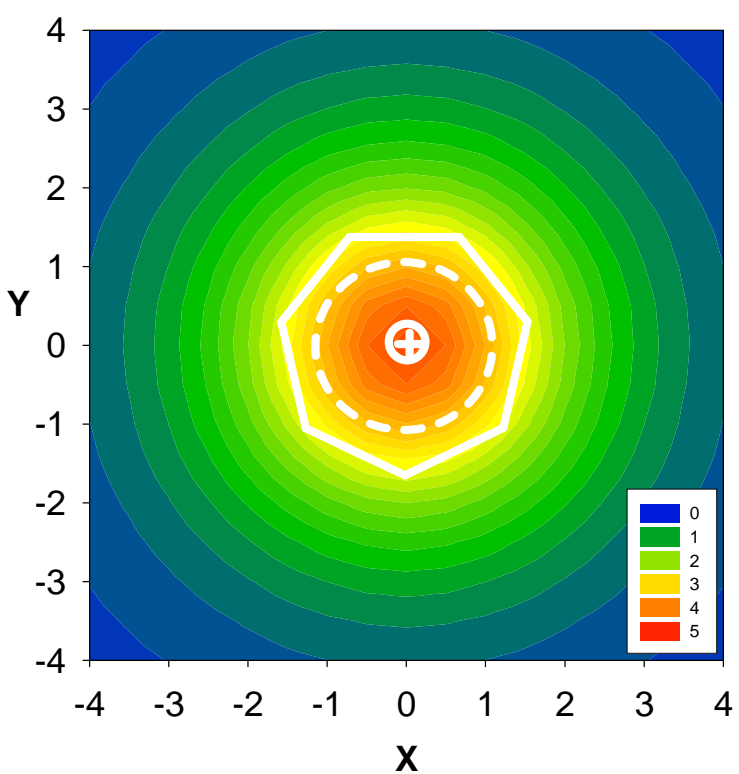

(b)

\subsection{Benzene fused to tropylium ion}

The shielding surface over the benzotropylium ion $\mathbf{1 5}$ has an elongated mound of shielding symmetrically displaced over both rings (Figure 11a). The maximum shielding is $4.67 \mathrm{ppm}$. This is comparable to the shielding increment for tropylium ion 14 at $2.5 \AA$ (4.52 ppm; Figure 10b) but greater than that reported for benzene $2(2.96 \mathrm{ppm})$ [5]. The large shielding effect over benzotropylium and tropylium ion is partly due to its positive charge, which attracts electron density to the proximal hydrogen of the probe molecule. The slightly enhanced shielding relative to tropylium ion is consistent 
with two opposing factors: fusion with a second aromatic ring, which increases shielding and delocalization of the positive charge over more atoms, which diminishes shielding. Calculations of the npa charge (Figure 2) show that the positive charge is widely distributed among the atoms, with the tropylium side of the structure bearing over $70 \%$ of the positive charge. Charge calculations per $\mathrm{C}-\mathrm{H}$ group give +0.08 e for the benzene ring and +0.14 e for the tropylium ring, disregarding the charge on the ring juncture carbons. All of the calculated charge is located on hydrogen; none is on carbon. Bond length calculations verify the delocalization of electron density; the bond lengths range from $1.36 \AA$ to $1.43 \AA ; \Delta d=0.07 \AA$. Interestingly, the greatest alternation in bond lengths is in the benzene portion of the structure. The tropylium side has bond lengths ranging from $1.38 \AA$ to $1.43 \AA ; \Delta d=0.05 \AA$.

The isotropic shielding increment surface of bisbenzotropylium ion 16 (Figure 11b) is an elongated curved mound encompassing all three rings. The maximum shielding value is $4.27 \mathrm{ppm}$, suggesting even greater delocalization of the charge in this structure compared to benzotropylium ion (above), although npa charge calculations ((Figure 2 ) indicate that about half of the positive charge is associated with the carbon and hydrogen atoms of the central (tropylium ion) ring in bisbenzotropylium ion 16, less than in benzotropylium ion 15. The mean charge per $\mathrm{C}-\mathrm{H}$ group (excluding the charges on ring juncture carbon atoms) is +0.08 e for the benzene rings and +0.17 e for the tropylium ring.

Figure 11. Isotropic shielding increment surfaces of (a) 15 and (b) 16.

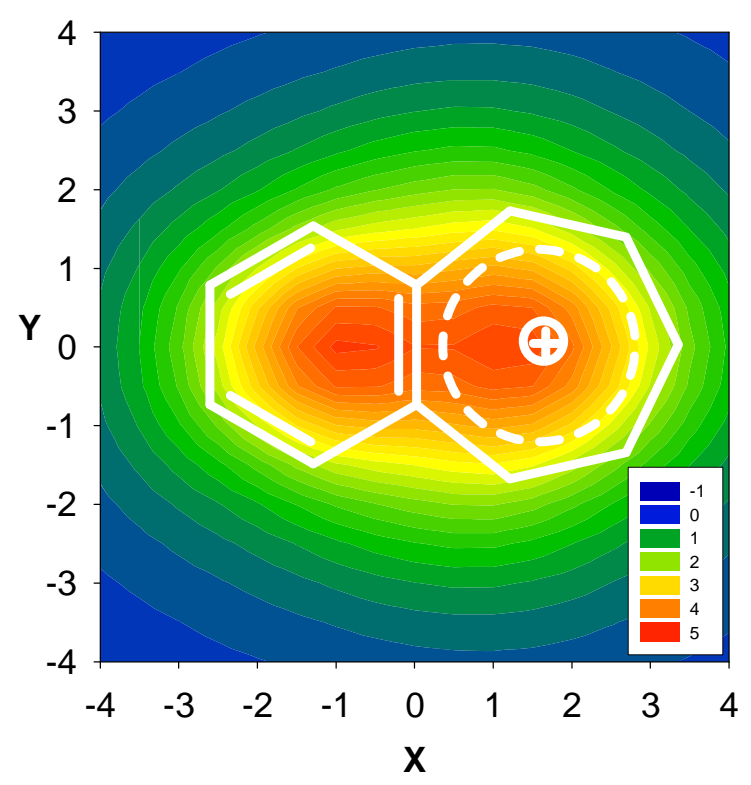

(a)

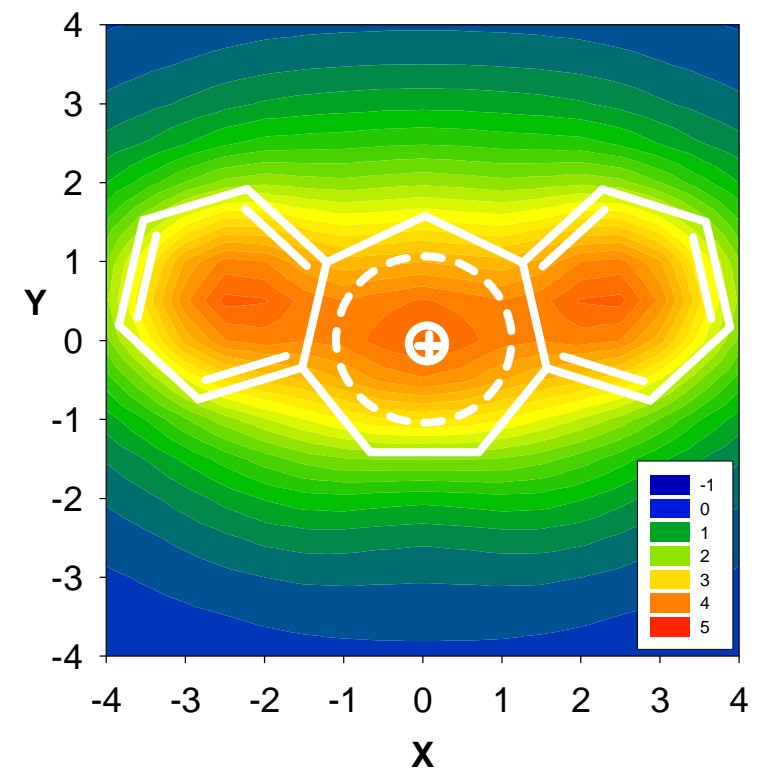

(b)

The isotropic shielding surface over trisbenzotropylium ion 17 (Figure 12) shows four connected mounds of substantial shielding. The benzene rings have shielding maxima at their centers that are nearly equal in magnitude (3.64 ppm and $3.66 \mathrm{ppm})$. The positive charge is widely distributed around the tropylium ring and also into the benzene rings ((Figure 2). The mean charge per $\mathrm{C}-\mathrm{H}$ group (excluding the charges on ring juncture carbon atoms) is +0.07 e for the two equivalent benzene rings (A), +0.08 e for the other benzene ring $(\mathrm{C})$ and +0.12 e for the tropylium ring. Delocalization of charge away from the central ring results in less maximum shielding than observed over tropylium ion 14 at $2.5 \AA$ (4.52 ppm, Figure 10b) and bisbenzotropylium ion 16 (4.27 ppm, Figure 11b) but greater shielding over the benzene rings than was observed over benzene 2 at $2.5 \AA$ ( 2.96 ppm, Figure $4 \mathrm{a}$ ). 
Figure 12. Isotropic shielding increment surface of 17.

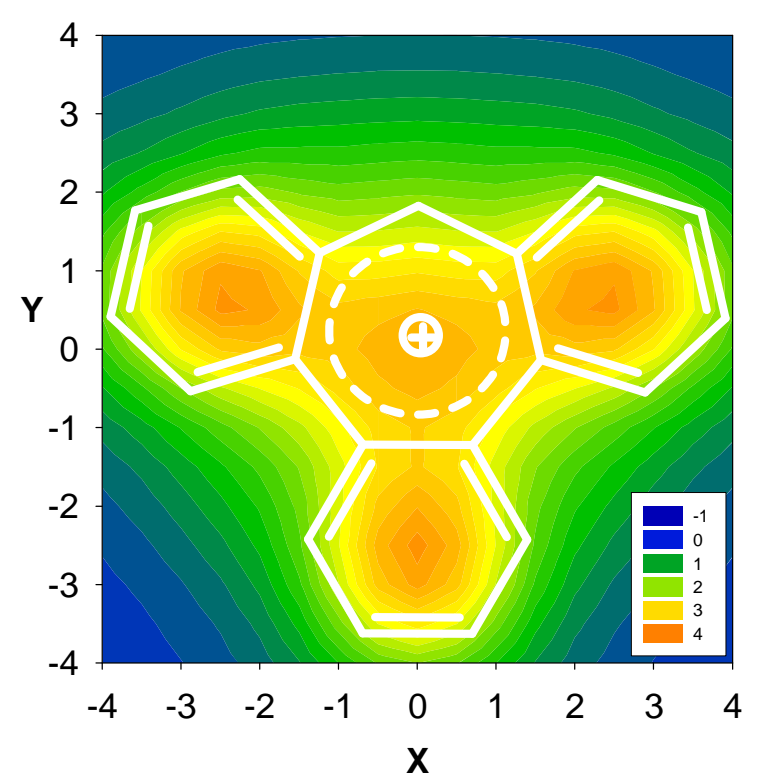

Table 2. Shielding increments $2.5 \AA$ over ring midpoints (and NICS(1) values) as labeled in Figure 2.

$\Delta \sigma$ and $(N I C S(1))$ in ppm above center of ring:

$\begin{array}{llll}\text { Structure } & \text { A } & \text { B } & \text { C }\end{array}$

\begin{tabular}{cccc}
\hline $\mathbf{1 1}$ & $2.36(-12.35)$ & $2.32(-16.97)$ & - \\
$\mathbf{1 2}$ & -- & $1.17(-14.03)$ & \\
$\mathbf{1 3}$ & $2.93(-12.56)$ & $2.61(-15.76)$ & -- \\
$\mathbf{1 4}$ & -- & $4.52(-11.22)$ & - \\
$\mathbf{1 5}$ & $4.51(-14.35)$ & $4.52(-10.56)$ & -- \\
$\mathbf{1 6}$ & $4.18(-13.41)$ & $4.22(-8.46)$ & $3.66(-12.13)$ \\
\hline
\end{tabular}

As seen in Table 2, for the ionic aromatic fused hydrocarbons NICS(1) and $\Delta \sigma$ values give opposite trrends for ring B. This is because $\Delta \sigma$ values are sensitive to charge [14], unlike NICS(1) values. The anions (11-14) cause electrostatic deshielding of the probe, somewhat offsetting the shielding effect of aromaticity. The cations (15-17) cause electrostatic shielding of the probe, thus enhancing the shielding effect of due to aromaticity. 


\section{Computational Section}

Equilibrium structures of each of the hydrocarbons in Figures 1 and 2 were obtained in Titan [33] using the using the HF/6-31G(d,p) level of theory and basis set [34]. These planar structures were oriented as indicated in Figures 1 and 2 with the atoms in the XY plane and their Cartesian coordinates were obtained. A diatomic hydrogen probe molecule oriented perpendicular to the plane of the hydrocarbon with the proximal hydrogen $2.5 \AA$ from the plane of the hydrocarbon was added the Cartesian coordinate description of each structure. This probe distance was selected because previous studies have shown that using a molecular probe that is closer than $2.5 \AA$ results in mutual perturbation of the probe orbitals and the $\pi$ bonds of the hydrocarbon, as that distance is less than the sum of the van der Waals radius of the probe molecule hydrogen and the effective radius of the $\pi$ bond [35, 36]. A series of single point GIAO calculations was performed in Gaussian 03 [37] on a $P Q S$ Linux cluster on these supramolecules using the same method and basis set, moving the $\mathrm{H}_{2}$ probe in $0.5 \AA$ increments in both the $\mathrm{X}$ and $\mathrm{Y}$ directions in separate calculations. Previous calculations [38] have shown that basis set superposition error, as measured by the counterpoise method of Boys and Bernardi [39], introduces a negligible effect on shielding values; BSSE is typically no greater than $0.05 \mathrm{ppm}$. Also, the difference between the shielding values obtained using single point calculations and constrained geometry-optimized calculations is also negligible [31]. The calculations covered a square grid that extended beyond the positions of the carbon atoms in the $\mathrm{X}$ and $\mathrm{Y}$ directions. The symmetry of some of the structures allowed only one-half or one-fourth of the grid to be calculated and the data to be replicated by a reflection across the $\mathrm{X}$ or $\mathrm{Y}$ axis (or $\mathrm{X}$ and $\mathrm{Y}$ axes). Isotropic shielding calculations were also performed with the diatomic hydrogen probe $2.5 \AA$ above the geometric midpoint of each ring. The shielding increment $(\Delta \sigma)$ at a given point in Cartesian space was determined by taking the difference between the calculated isotropic shielding value of one of the hydrogens in the $\mathrm{H}_{2}$ probe alone $(26.77 \mathrm{ppm})$ and that of the proximal hydrogen of the $\mathrm{H}_{2}$ probe at that point relative to the polycyclic hydrocarbon structure. Computed isotropic shift values greater than that of isolated $\mathrm{H}_{2}$ result in positive (shielding) $\Delta \sigma$ values; those with smaller values yield negative (deshielding) $\Delta \sigma$ values. The shielding increments $(\Delta \sigma)$ are therefore equal in magnitude but opposite in sign to differences in ${ }^{1} \mathrm{H}-\mathrm{NMR}$ chemical shifts $(\Delta \delta)$. Three-dimensional NMR shielding increment surfaces ( $\Delta \sigma v s . \mathrm{X}$ and $\mathrm{Y}$ at a fixed value of $\mathrm{Z}$ ) were prepared using SigmaPlot [40] to represent graphically the locations and magnitudes of shielding over the molecules in the study. NICS(1) values [3] and natural population analysis charges [32] were computed using the same level of theory and basis set.

\section{Conclusions}

GIAO-HF/6-31G(d,p) calculations were performed to determine the isotropic shielding value of the proximal hydrogen of a diatomic hydrogen probe located at various positions perpendicular to the plane $2.5 \AA$ above a series of fused ring hydrocarbons. These fused ring hydrocarbons are combinations of benzene fused to cyclobutadiene, benzene fused to cyclopentadienyl anion, or benzene fused to tropylium ion. The isotropic shielding value $(26.77 \mathrm{ppm})$ of hydrogen in diatomic hydrogen was subtracted from each of the above calculated shielding values to obtain the shielding increment $(\Delta \sigma)$. Three dimensional NMR shielding increment surfaces are presented for each of these 
hydrocarbons. In most instances, the shielding increment surface shows the expected region of shielding over aromatic (benzene, cyclopentadienyl anion, tropylium ion) rings and the region of deshielding expected over antiaromatic (cyclobutadiene) rings. However, in a few structures, unexpected shielding increment surfaces were obtained. In these unexpected cases, examination of computed bond lengths and natural population analysis atomic charges led to an understanding of the observed shielding effects, generally interpreted in terms of localized $\pi$ bonds or polarization effects. Bond length calculations and (where available) X-ray data were examined to ascertain the degree of localization (or delocalization) of $\pi$ bonds. Results were compared with published current density maps for several of the structures; they were consistent. Among the benzene-cyclobutadiene fused ring hydrocarbons, six membered rings with adjacent formal cyclobutene rings (ring $A$ in 1, 4, 5 and 6) have very little aromaticity, but external six membered rings connected to formal cyclobutane rings (ring $A$ in 7, 8, 9 and 10) are aromatic. Computed shielding increments $(\Delta \sigma)$ above the six-membered rings of the eight benzene-cyclobutadiene fused hydrocarbons in the study correlate well $(\mathrm{r}=0.98)$ with NICS(1) values; correlation was also good $(\mathrm{r}=0.92)$ between $\Delta \sigma$ and NICS(1) computed above the four membered rings in those structures. Both methods are used for evaluating aromaticity.

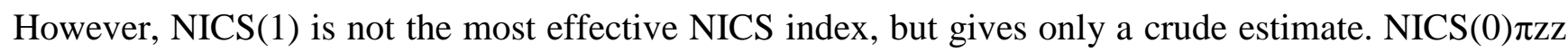
is considered to be the best NICS method [6].

\section{Acknowledgements}

The authors gratefully acknowledge support of this work by the donors of the Petroleum Research Fund, administered by the American Chemical Society. This manuscript is dedicated to Paul v. R. Schleyer for his remarkable career accomplishments leading to a better understanding of the concept of aromaticity. The author wishes to thank Paul Schleyer, Judy Wu and Yan Wang for helpful discussion and valuable assistance in proofreading the manuscript.

\section{References and Notes}

1. Cyrañsky, M.K.; Krygowski, T.M.; Katritsky, A.R.; Schleyer, P.v.R. To what extent can aromaticity be defined uniquely? J. Org. Chem. 2002, 67, 1333-1338.

2. Hückel, E. Quantentheoretische Beiträge zum Benzolproblem I. Die Elektronenkonfiguration des Benzols und verwandter Verbindungen. Z. Phys. 1931, 70, 204-286.

3. Schleyer, P.v.R.; Maerker, C.; Dransfeld, A.; Jiao, H.J.; Hommes, N.J.R.v.E. Nucleus-independent chemical shifts: a simple and efficient aromaticity probe. J. Am. Chem. Soc. 1996, 118, 6317.

4. Schleyer, P.v.R.; Manoharan, M.; Wang, Z-.X.; Kiran, B.; Jiao, H.; Puchta, R.; Hommes, N.J.R.v.E. Dissected Nucleus-Independent Chemical Shift Analysis of $\pi$-Aromaticity and Antiaromaticity. Org. Lett. 2001, 3, 2465-2468.

5. Chen, Z.; Wannere, C.S.; Corminboeuf, C.; Puchta, R.; Schleyer, P.v.R. Nucleus-Independent Chemical Shifts (NICS) as an Aromaticity Criterion. Chem. Rev. 2005, 105, 3842-3888.

6. Fallah-Bagher-Shaidaei, H.; Wannere, C.S.; Corminboeuf, C.; Puchta, R.; Schleyer, P.v.R. Which NICS Aromaticity Index for Planar $\pi$ Rings Is Best? Org. Lett. 2006, 8, 863-866. 
7. Corminboeuf, C.; Heine, T.; Seifert, G.; Schleyer, P.v.R.; Weber, J. Induced magnetic fields in aromatic [n]-annulenes-interpretation of NICS tensor components. Phys. Chem. Chem. Phys. 2004, 6, 273-276.

8. Kleinpeter, E.; Klod, S. Ab initio calculation of the anisotropy effect of multiple bonds and the ring current effect of arenes-application in conformational and configurational analysis. J. Chem. Soc. Perkin Trans. 2001, 2, 1893-1898.

9. Martin, N.H.; Caldwell, B.C.; Carlson. K.P.; Teague, M.R. Ab initio calculation of through-space magnetic shielding of linear polycyclic aromatic hydrocarbons (acenes): Extent of aromaticity. $J$. Mol. Graph. Modell. 2009, 27, 689-692.

10. Alkorta, I.; Rozas, I.; Elguero, J. An ab initio study of the NMR properties (absolute shieldings and NICS) of a series of significant aromatic and antiaromatic compounds. Tetrahedron 2001, 57, 6043-6049.

11. Schulman, J.M.; Disch, R.L.; Jiao, H.; Schleyer, P.v.R. Chemical Shifts of the [N]Phenylenes and Related Compounds. J. Chem. Phys. A 1998, 102, 8051-8055.

12. Kleinpeter, E.; Klod, S.; Koch, A. Visualization of through space NMR shieldings of aromatic and anti-aromatic molecules and a simple means to compare and estimate aromaticity. J. Mol. Struct. (THEOCHEM) 2007, 811, 45-60.

13. Stanger, A. Nucleus-Independent Chemical Shifts (NICS): Distance Dependence and Revised Criteria for Aromaticity and Antiaromaticity. J. Org. Chem. 2006, 71, 883-893.

14. Martin, N.H.; Loveless, D.M.; Main, K.L.; Wade, D.C. Computation of through-space NMR shielding effects by small-ring aromatic and antiaromatic hydrocarbons. J. Mol. Graph. Modell. 2006, 25, 389-395.

15. Martin, N.H.; Rowe, J.E.; Pittman, E.L. Computed NMR shielding increments over unsaturated five-membered ring heterocyclic compounds as a measure of aromaticity. J. Mol. Graph. Modell. 2009, 28, 853-859.

16. Martin, N.H.; Rowe, J.E.; Pittman, E.L. Computed NMR shielding increments over benzo-analogs of unsaturated five-membered ring heterocyclic compounds as a measure of aromaticity. J. Mol. Graph. Modell. 2010, 28, 650-656. http://dx.doi.org/10.1016/j.jmgm.2010.01.005.

17. Siegel, J.S. Mills-Nixon Effect: Wherefore Art Thou? Angew. Chem. Int. Ed. Engl. 1994, 33 1721-1723, and references cited therein.

18. Neidlein, R.; Christen, D.; Poignée, V.; Boese, R.; Bläser, D.; Gieren, A.; Ruiz-Perez, C.; Hübner, T. The Structures of 1H-Cyclopropabenzene and Its 1,1-Bis(triisopropylsilyl) Derivative. Angew. Chem. Int. Ed. Engl. 1988, 27, 294-295.

19. Boese, R.; Bläser, D. Structures and Deformation Electron Densities of 1,2-Dihydrocyclobutabenzene and 1,2,4,5-Tetrahydrodicyclobuta[a,d]benzene. Angew. Chem. Int. Ed. Engl. 1988, 27, 304-305.

20. Stanger, A. Is the Mills-Nixon Effect Real? J. Am. Chem. Soc. 1991, 113, 8277-8280.

21. Soncini, A.; Havenith, R.W.A.; Fowler, P.W.; Jenneskens, L.W.; Steiner, E. Control of the Diatropic $\pi$ Ring Current in Strained Benzenes: Effects of Annelation with Cyclopropa, Cyclobuta, and Cyclobutadieno Clamping Groups. J. Org. Chem. 2002, 67, 4753-4758. 
22. Steinmann, S.N.; Jana, D.F.; Wu, J.I.-C.; Schleyer, P.v.R.; Mo, Y.; Corminboeuf, C. Direct Assessment of Electron Delocalization Using NMR Chemical Shifts. Angew. Chem. Int. Ed. 2009, 48, 9828-9833.

23. Alkorta, I.; Elguero, J. Ab initio hybrid DFT-GIAO calculations of the shielding produced by carbon-carbon bonds and aromatic rings in ${ }^{1} \mathrm{H}-\mathrm{NMR}$ spectroscopy. New J. Chem. 1998, 381-385.

24. Fawcett, J. K.; Trotter, J. A refinement of the structure of biphenylene. Acta Crystallogr. 1966, 20, 87-93.

25. Toda, F.; Garratt, P. Four-Membered Ring Compounds Containing Bis(methylene)cyclobutene or Tetrakis(methylene)cyclobutane Moieties. Benzocyclobutadiene, Benzodicyclobutadiene, Biphenylene, and Related Compounds. Chem. Rev. 1992, 92, 1685-1707.

26. Berris, B.C.; Hovakeemian, G.H.; Lai, Y.-H.; Mestdagh, H; Vollhardt, K.P.C. A New Approach to the Construction of Biphenylenes by the Cobalt-Catalyzed Cocyclization of o-Diethynylbenzenes with Alkynes. Application to an Iterative Approach to [3]Phenylene, the First Member of a Novel Class of Benzocyclobutadienoid Hydrocarbons. J. Am. Chem. Soc. 1985, 107, 56705687.

27. Kleinpeter, E.; Koch, A. Trisannelated benzenes - Aromatic molecules or 1,3,5-cyclohexatriene derivatives subjected to magnetic properties. J. Mol. Struct. (THEOCHEM) 2008, 857, 89-94.

28. Diercks, R.; Vollhardt, K.P.C. Novel Synthesis of the Angular [3]Phenylene (Terphenylene) by Cobalt-Catalyzed Cyclization of Bis(2-ethynylphenyl)ethyne: a Molecule With an Internal Cyclohexatriene Ring. Angew. Chem., Int. Ed. Engl. 1986, 25, 266-268.

29. Fowler, P.W.; Havenith, R.W.A.; Jenneskens, L.W.; Soncini, A.; Steiner, E. Survival and extinction of delocalised ring currents in clamped benzenes. Chem. Commun. 2001, 22, 23862387.

30. Diercks, R.; Vollhardt, K.P.C. Tris(benzocyclobutadieno)benzene, the Triangular [4]Phenylene with a Completely Bond-Fixed Cyclohexatriene Ring: Cobalt-Catalyzed Synthesis From Hexaethynylbenzene and Thermal Ring Opening to 1,2:5,6:9,10-Tribenzo-3,4,7,8,11,12hexadehydro[12] annulene. J. Am. Chem. Soc. 1986, 108, 3150-3152.

31. Martin, N.H.; Loveless, D.M.; Wade, D.C. A comparison of calculated NMR shielding probes. $J$. Mol. Graph. Modell. 2004, 23, 285-290, and references cited therein.

32. Reed, A.E.; Weinstock, R.B.; Weinhold, F. Natural population analysis. J. Chem. Phys. 1985, 83, 735-746.

33. Titan, Version 1.0.1; Wavefunction Inc., Schrödinger, Inc.: Portland, OR, 1999.

34. Hehre, W.J.; Radom, L.; Schleyer, P.v.R.; Pople, J.A. Ab Initio Molecular Orbital Theory; Wiley, New York, USA, 1986.

35. Martin, N.H.; Allen, N.W., III; Minga, E.K.; Ingrassia, S.T. An Empirical Proton NMR Shielding Equation for Alkenes based on Ab Initio Calculations. Struct. Chem. 1998, 9, 403-410.

36. Martin, N.H.; Brown, J.D.; Nance, K.H.; Schaefer, H.F., Jr.; Schleyer, P.v.R.; Wang, Z.-X.; Woodcock, H.L. Analysis of the Origin of Through-Space Proton NMR Deshielding by Selected Organic Functional Groups. Org. Lett. 2001, 3, 3823-3826.

37. Frisch, M.J.; Trucks, G.W.; Schlegel, H.B.; Scuseria, G.E.; Robb, M.A.; Cheeseman, J.R.; Montgomery, J.A., Jr.; Vreven, T.; Kudin, K.N.; Burant, J.C.; Millam, J.M.; Iyengar, S.S.; Tomasi, J.; Barone, V.; Mennucci, B.; Cossi, M.; Scalmani, G.; Rega, N.; Petersson, G.A.; 
Nakatsuji, H.; Hada, M.; Ehara, M.; Toyota, K.; Fukuda, R.; Hasegawa, J.; Ishida, M.; Nakajima, T.; Honda, Y.; Kitao, O.; Nakai, H.; Klene, M.; Li, X.; Knox, J.E.; Hratchian, H.P.; Cross, J.B.; Adamo, C.; Jaramillo, J.; Gomperts, R.; Stratmann, R.E.; Yazyev, O.; Austin, A.J.; Cammi, R.; Pomelli, C.; Ochterski, J.W.; Ayala, P.Y.; Morokuma, K.; Voth, G.A.; Salvador, P.; Dannenberg, J.J.; Zakrzewski, V.G.; Dapprich, S.; Daniels, A.D.; Strain, M.C.; Farkas, O.; Malick, D.K.; Rabuck, A.D.; Raghavachari, K.; Foresman, J.B.; Ortiz, J.V.; Cui, Q.; Baboul, A.G.; Clifford, S.; Cioslowski, J.; Stefanov, B.B.; Liu, G.; Liashenko, A.; Piskorz, P.; Komaromi, I.; Martin, R.L.; Fox, D.J.; Keith, T.; Al-Laham, M.A.; Peng, C.Y.; Nanayakkara, A.; Challacombe, M.; Gill, P.M.W.; Johnson, B.; Chen, W.; Wong, M.W.; Gonzalez, C.; Pople, J.A. Gaussian 03, Revision B.01; Gaussian Inc.: Pittsburgh, PA, 2003.

38. Martin, N.H.; Floyd, R.M.; Woodcock, H.L.; Huffman, S.; Lee, C.-K. Computation of throughspace NMR shielding effects in aromatic ring pi-stacked complexes J. Mol. Graph. Modell. 2008, 26, 1125-1130.

39. Boys, S.F.; Bernardi, F. The calculations of small molecular interaction by the difference of separate total energies. Some procedures with reduced error. Mol. Phys. 1970, 19, 553-566.

40. SigmaPlot 2004 for Windows, Version 9.01; Systat Software, Inc.; San Jose, CA, 2004.

(C) 2010 by the authors; licensee Molecular Diversity Preservation International, Basel, Switzerland. This article is an open-access article distributed under the terms and conditions of the Creative Commons Attribution license (http://creativecommons.org/licenses/by/3.0/). 